\title{
Activation of metabotropic glutamate receptor type $2 / 3$ supports the involvement of the hippocampal mossy fiber pathway on contextual fear memory consolidation
}

\author{
Stéphanie Daumas, ${ }^{1,2,3}$ Johnatan Ceccom, ${ }^{1,2}$ Hélène Halley, ${ }^{1,2}$ Bernard Francés, ${ }^{1,2}$ \\ and Jean-Michel Lassalle ${ }^{1,2,4}$ \\ ${ }^{1}$ Université de Toulouse, 31042 Toulouse Cedex 9, France; ${ }^{2}$ CNRS, UMR 5169, Centre de Recherches sur la Cognition Animale, \\ Université Paul Sabatier, 31062 Toulouse Cedex 4, France
}

\begin{abstract}
Elucidating the functional properties of the dentate gyrus (DG), CA3, and CA1 areas is critical for understanding the role of the dorsal hippocampus in contextual fear memory processing. In order to specifically disrupt various hippocampal inputs, we used region-specific infusions of DCG-IV, the metabotropic glutamate receptor agonist, which selectively disrupts entorhinal outputs as well as mossy fiber transmission in the hippocampus. The consequences of these injections were studied using a contextual fear conditioning (CFC) paradigm. Selective contextual memory impairment was observed in DG- and CA3-, but not in CA1-treated mice. Our results emphasize the major role played by the DG and CA3 areas in the early phases of contextual memory processing, particularly during the acquisition and early consolidation phases of CFC.
\end{abstract}

In the hippocampal trisynaptic network, the dentate gyrus (DG) receives inputs from the entorhinal cortex via the perforant path (PP). DG mossy fibers contact CA3 pyramidal cells (MF-CA3), which in turn send their axons, the Schaffer collaterals, to CA1 pyramidal cells (SC-CA1). In addition, entorhinal inputs also project directly to CA3 and CA1 (see Fig. 1). Nakazawa et al. (2002, 2004), and Rolls and Kesner (2006) have recently updated the distinct mnemonic roles that have been attributed to each of the hippocampal subfields and inputs (see also Kesner et al. 2004). According to their hypothesis, the DG area is involved in pattern separation of similar spatial memories, the recurrent CA3 network is crucial for the storage of associative memories and their recall by pattern completion, whereas the CA1 area is instrumental for object or context novelty recognition. The CA1 system is also thought to be involved in the recall process and to make a special contribution to temporal aspects of memory, including associations over a delay period and sequence memory. These three major hippocampal areas operate as a feed-forward sequential processing system. Our previous research has demonstrated the important neuromodulatory role played by zinc and dynorphin at the MFCA3 synapse in the acquisition and consolidation of contextual fear memory (Daumas et al. 2004, 2007). To further elucidate the functional properties of CA3, this research investigates the role of various glutamatergic entorhinal inputs to DG, CA3, and CA1 regions. Glutamate is involved in all aspects of cognitive function since it is the excitatory transmitter of cortical and hippocampal pyramidal neurons. This transmitter activates both ionotropic receptors and a family of at least eight G-protein-coupled metabotropic glutamate receptors (mGluR receptors) subdivided into three groups: group I receptors, mGluR1 and mGluR5; group II receptors, mGluR2 and mGluR3; and group III receptors, mGluR4,

\footnotetext{
${ }^{3}$ Present address: Centre for Cognitive and Neural Systems, University of Edinburgh, Edinburgh EH8 9JZ, UK. ${ }^{4}$ Corresponding author.

E-mail lassalle@cict.fr; fax 33-561-556-154.

Article is online at http://www.learnmem.org/cgi/doi/10.1101//m.1418309.
}

mGluR6, mGluR7, and mGluR8 (Conn and Pin 1997). Whereas group I mGluR are primarily localized postsynaptically, groups II and III receptors are typically presynaptic (Cartmell and Schoepp 2000). Of the group II mGluRs, mGluR3 is highly expressed in glia, while mGluR2 is largely neuronal (Ohishi et al. 1998). Considerable pharmacological evidence suggests that group II mGluRs can markedly inhibit synaptic transmission (Anwyl 1999; Cartmell and Schoepp 2000). Application of (2S, $\left.1^{\prime} R, 2^{\prime} R, 3^{\prime} R\right)-2-(2,3-$ dicarboxycyclopropyl)glycine (DCG-IV), a specific mGluRIIagonist, reversibly suppresses field excitatory postsynaptic potentials evoked by mossy fiber stimulation at MF-CA3 synapses in rat hippocampal slices (Scanziani et al. 1997; Klausnitzer and Manahan-Vaughan 2008). DCG-IV is inactive at the commissural/ associational input to CA3 and at the Schaffer collateral/commissural input to CA1 regions (Kamiya et al. 1996). However, DCG-IV application to hippocampal slices leads to a decrease in synaptic transmission between (1) perforant path and CA1 pyramidal cells (PP-CA1) of $80 \%$, (2) PP-CA3 of $77.7 \%$, and (3) MF-CA3 of $70 \%$ (Tsukamoto et al. 2003).

Our study was primarily designed to compare the effects of the inactivation by DCG-IV of the direct entorhinal pathways to CA1 and CA3, and of the indirect pathway to CA3 through the DG and MF.

In this work, stereotaxic injections of small volumes of DCGIV in different hippocampal areas (DG, CA3, and CA1) allowed us to reversibly inhibit glutamatergic transmission in each region. The consequences of these injections were studied using a contextual fear conditioning (CFC) paradigm (Rudy et al. 2004). Briefly, contextual fear conditioning consisted of a single training session with two trials separated by an intertrial interval (ITI) of $120 \mathrm{sec}$. In this protocol, the context appears in the background, since the 2 -sec electric shock is coupled with a 30-sec tone. Twenty-four hours after training, contextual learning was checked under the same experimental conditions as training, for $4 \mathrm{~min}$. Two hours later, mice were tested for freezing to the tone (cue fear conditioning) in a modified context, where they received a 2-min tone presentation, 2 min after their introduction in the cage. Freezing 


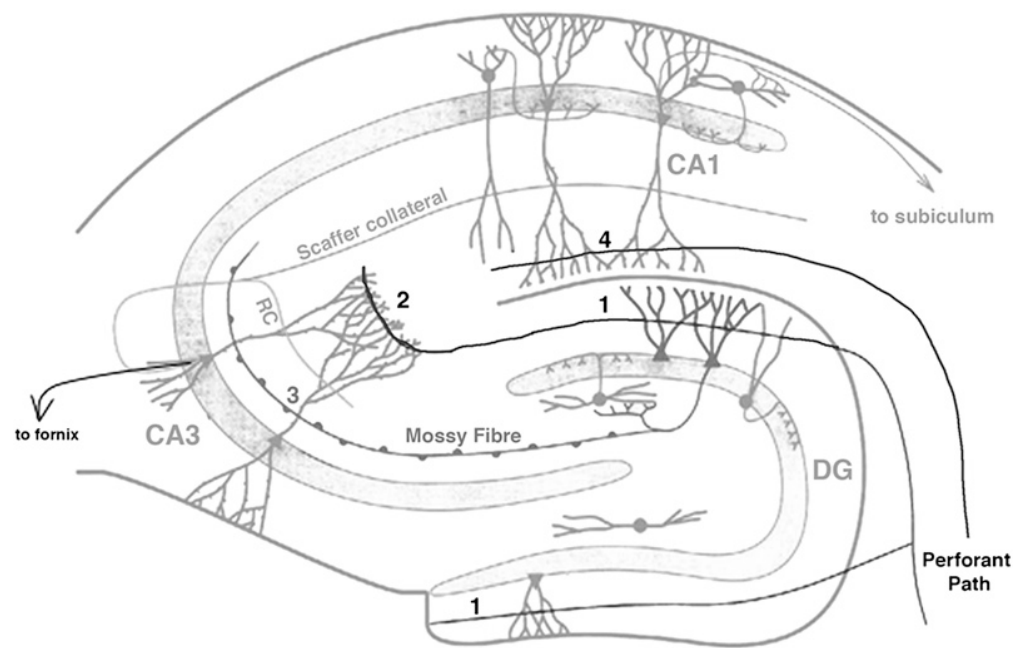

Figure 1. Schematic representation of the hippocampal circuits that the mGluR2 agonist DCG-IV should inactivate. (DG) Infusions of DCG-IV should block the synapses between the perforant path and the granule cells of the dentate gyrus (1), and by consequence abolish the mossy fiber pathway signal to CA3, weakening the CA3 network. (CA3) Infusions of DCG-IV should block both perforant path-CA3 (2), and mossy fibers-CA3 (3), allowing an almost complete CA3 inactivation. (CA1) Infusions of DCGIV should block the perforant path to CA1 (4); multimodal information should only be processed through the trisynaptic circuit shedding light on the role of entorhinal outputs to CA1 in contextual memory processing. (Figure adapted from Rolls and Treves [1998] and reprinted here with permission from Oxford University Press (01998.) (DG) Dentate gyrus; (RC) recurrent collateral.

was scored every 5 sec during training and test sessions. Freezing is defined as the lack of all movement other than respiration. Data were converted to the percentage of samples scored at freezing for the 4-min context period and the 2-min tone presentation. Three-month-old C57BL/6JIco male mice were implanted bilaterally with guide cannulae into the dorsal hippocampus according to stereotaxic coordinates from the Franklin and Paxinos atlas (Franklin and Paxinos 1997): DG and CA1: AP $-1.6 \mathrm{~mm}, \mathrm{ML} \pm 1 \mathrm{~mm}$, and DV: $-1.2 \mathrm{~mm}$ from skull, CA3: AP -1.6 $\mathrm{mm}, \mathrm{ML} \pm 2.5 \mathrm{~mm}$, and DV $-1.5 \mathrm{~mm}$ from skull, so that the tip of the guide was close to the dorsal part of the hippocampus, above the CA1 field or the CA3 area. All infusions were made on freely moving mice, at a rate of $0.11 \mu \mathrm{L} / \mathrm{min}(0.25 \mu \mathrm{L}$ per hippocampus). The tip of the infusion cannulae finishes $1.1 \mathrm{~mm}$ below the guide cannulae for the DG and CA3 regions, and $0.5 \mathrm{~mm}$ for the CA1. Surgical, intracerebral infusion, behavioral, and histological procedures followed Daumas et al. (2004, 2005, 2007). DCG-IV was supplied by Tocris, dissolved in saline, and prepared fresh on the day of infusion. After histological examination of the brains, 29 mice out of 171 were taken out of the analyses because of misplacement of the guide or injection cannulae.

A preliminary experiment (Fig. 2A,B) aimed at choosing the optimal dose of DCG-IV to be infused in the CA3 area in order to act specifically on contextual fear conditioning. Five groups of mice were infused bilaterally with increasing doses of DCG-IV in the CA3 area of the dorsal hippocampus $15 \mathrm{~min}$ before the conditioning session: $0-\mathrm{NaCl}(n=7), 0.1$ $(n=9), 0.25(n=9), 0.5(n=9)$, and 1 $\mathrm{nmol} / 0.25 \mu \mathrm{L}(n=4)$. Due to side effects, the 1-nmol group was excluded from the analyses. The ANOVA revealed a significant variation among freezing levels expressed in the different groups during the context test given $24 \mathrm{~h}$ later $\left(F_{(3,30)}=\right.$ $9.44, P<0.001)$. Post-hoc analyses, using the Fisher's least significant difference (LSD) comparison test, revealed a significant dose-dependent impairment of contextual learning. On the other hand, there was no significant variation among the different groups for freezing responses to the tone $\left(F_{(3,30)}=0.289, P=\right.$ 0.833 ; Fig. 2B), although a significant decrease was observed for the highest dose $(1 \mathrm{nmol})$. Accordingly, in further experiments we used the $0.25-\mathrm{nmol}$ dose, since this dose was efficient to disturb the learning process with no effect on locomotion (data not shown). In a following preliminary study, the kinetics of the effects of DCG-IV was then assessed in the CA3 area of the dorsal hippocampus. Four different delays were chosen between the time of injection and the beginning of the conditioning session: $15 \mathrm{~min}, 1.5 \mathrm{~h}, 3 \mathrm{~h}$, and $6 \mathrm{~h}$. A control group injected with $\mathrm{NaCl}$ was run for each DCG-IV-treated group (15 min: NaCl, $n=4$; DCG-IV, $n=5 ; 1 \mathrm{~h} 30$ : NaCl, $n=4$; DCG-IV, $n=7 ; 3$ h: NaCl, $n=5$; DCG-IV, $n=7 ; 6$ h: NaCl, $n=5$; DCG-IV, $n=5$ ). Within $15 \mathrm{~min}$, the effect of DCG-IV reached its maximum, which lasted up to $3 \mathrm{~h}$ after injection (data not shown). According to the time course of the effect of DCG-IV, administration
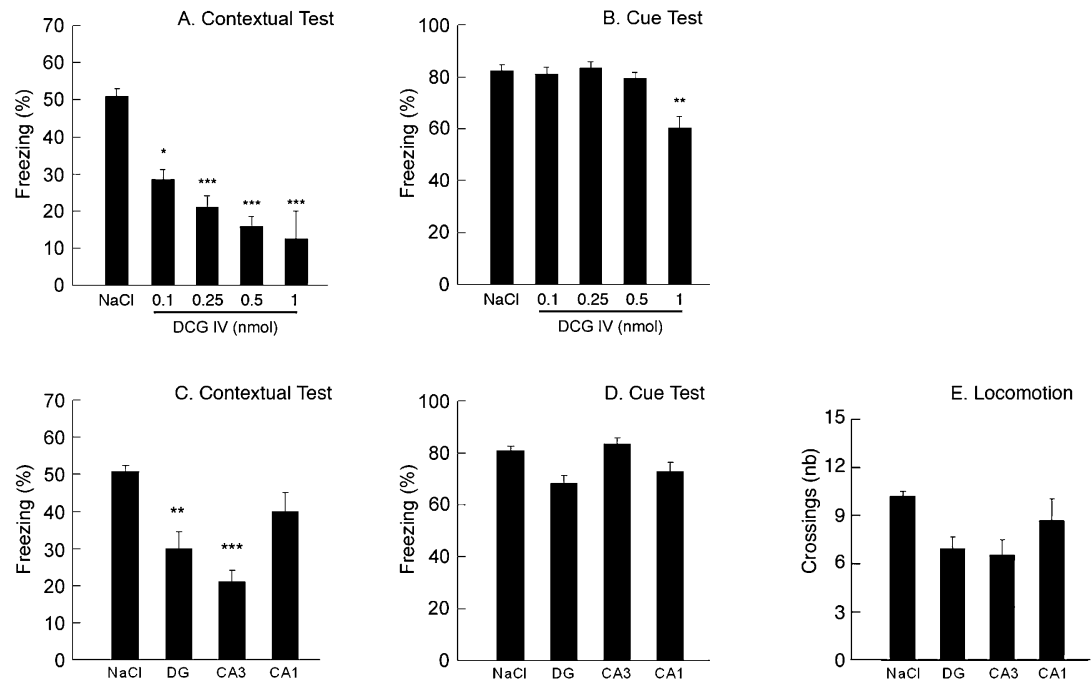

Figure 2. Freezing responses during contextual and tone memory retrieval $24 \mathrm{~h}$ after DCG-IV preconditioning injection in the dorsal hippocampus. $(A, B)$ Effects of increasing doses of DCG-IV infused before conditioning in the CA3 area of the dorsal hippocampus on freezing responses (mean \pm SEM) during recall tests to the context $(A)$ and to the tone $(B) .(C, D)$ Freezing responses during contextual $(C)$ and tone $(D)$ memory retrieval $24 \mathrm{~h}$ after DCG-IV preconditioning injection $(0.25 \mathrm{nmol})$ in DG, CA3, and CA1 of the dorsal hippocampus. (C) Infusions of DCG-IV in the DG and CA3 but not in the CA1 areas resulted in significant decreases of freezing responses to the context compared with $\mathrm{NaCl}$ controls. $(D)$ The drug infusions had no significant effect on freezing to the tone. $(E)$ The $0.25-\mathrm{nmol}$ dose had no significant effects on mice locomotion. $\left(^{*}\right) P<0.05,\left({ }^{* *}\right) P<0.01,\left({ }^{* * *}\right) P<0.001$ vs. $\mathrm{NaCl}$ injection. 
of the drug in CA3 15 min before the conditioning session results in impaired hippocampal activity during both the memory acquisition and consolidation of the task.

After these preliminary experiments, six groups of mice were infused either with a 0.25-nmol dose of DCG-IV or an equivalent volume of $\mathrm{NaCl}$ (as a control), into the CA1-, CA3-, or DGhippocampal areas $15 \mathrm{~min}$ before the conditioning session (CA1: DCG-IV $n=10, \mathrm{NaCl} n=5$; CA3: DCG-IV $n=9$, NaCl $n=7$; DG: DCG-IV $n=7, \mathrm{NaCl} n=4$ ). The aim of the first experiment was to determine the involvement of the entorhinal outputs to hippocampal subregions in early contextual memory processing, i.e., acquisition and/or consolidation phases. As mice from the three control groups exhibited similar results during the context retrieval test $\left(F_{(2,13)}=0.125, P=0.884\right)$ and to the tone retrieval test $\left(F_{(2,13)}=1.019, P=0.388\right)$, they were pooled in a single $\mathrm{NaCl}$ control group $(n=16)$. There was a significant overall effect of drug (DCG-IV vs. $\mathrm{NaCl})$ in the different hippocampal areas $\left(F_{(3,38)}=\right.$ 6.364, $P=0.001$; Fig. 2C). Post-hoc analyses showed that injections of DCG-IV in the CA3 $(P<0.001)$ and DG $(P=0.013)$ areas significantly impaired contextual freezing levels, whereas they did not significantly impair context freezing when infused in the CA1 $(P=0.178)$. Figure 2D shows freezing levels expressed by mice infused with DCG-IV in different hippocampal areas in response to the tone. No significant variation appeared among the groups $\left(F_{(3,38)}=2.154, P=0.109\right)$. Figure 2 E shows locomotor activity scores in these groups. The ANOVA failed to detect any significant variation $\left(F_{(3,38)}=1.138, P=0.346\right)$ due to a possible side effect of DCG-IV.

In order to test the effects of DCG-IV on consolidation of contextual fear memory without disturbing the acquisition process, the second experiment analyzed the effects of the postconditioning injection of $0.25 \mathrm{nmol}$ of DCG-IV in the different hippocampal areas (DG, $n=7$; CA3, $n=7$; CA1, $n=8$ ). In this second experiment, the infusion was made immediately after the training session. Again, as the different control groups that were injected $\mathrm{NaCl}$ in the DG $(n=5), \mathrm{CA} 3(n=4)$, and CA1 $(n=5)$ areas presented no significant variations of freezing levels either to the context $\left(F_{(2,11)}=0.841, P=0.457\right)$ or to the tone $\left(F_{(2,11)}=1.333\right.$, $P=0.303)$ during retrieval tests, they were pooled in a single $\mathrm{NaCl}$ control group $(n=14)$. Figure 3 displays freezing levels expressed during context (Fig. 3A) or tone (Fig. 3B) retrieval tests, by the different groups. There was a significant group effect on freezing levels to the context $\left(F_{(3,32)}=4.422, P=0.01\right)$, but not to the tone $\left(F_{(3,32)}=0.941, P=0.433\right)$. Post-hoc analyses showed significant differences between $\mathrm{NaCl}$ vs. DCG-IV in DG $(P=0.037)$, DCG-IV in CA3 $(P=0.003)$, whereas in CA1 the two groups did not differ $(P=0.769)$.

To assess whether the memory impairments observed in the first experiment are due to either the sole acquisition or consolidation disruption, or both, we decided to directly compare the
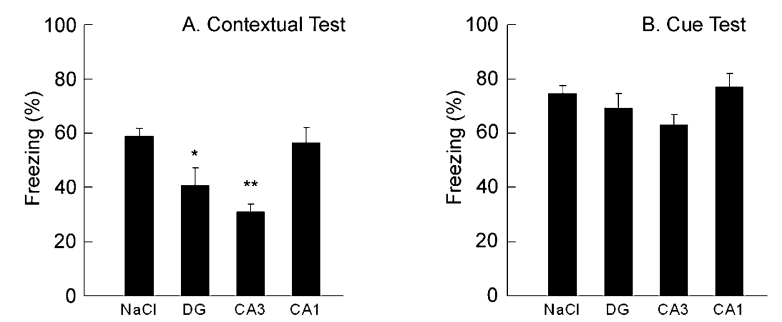

Figure 3. Effect of postconditioning injection of DCG-IV in the different hippocampal areas on freezing responses during contextual and tone memory retrieval. Infusions of DCG-IV in the DG and CA3, but not in the CA1 areas significantly decreased the freezing responses to the context $(A)$, but they had no significant effect on the level of freezing responses to the tone $(B) .\left(^{*}\right) P<0.05,\left({ }^{* *}\right) P<0.01$ vs. $\mathrm{NaCl}$ injection. results from the first experiment (preconditioning infusion) with the one from the second experiment (postconditioning infusion). No significant difference appeared in any group according to the time of the injection before or after the conditioning session: DG $\left(F_{(1,12)}=0.892, P=0.364\right)$; CA3 $\left(F_{(1,14)}=2.550, P=0.133\right)$; CA1 $\left(F_{(1,16)}=1.538, P=0.233\right)$, arguing for a main action of the drug on the early consolidation phase.

To summarize, two preliminary experiments studied DCG-IV dose effects and kinetics on preconditioning injections in the dorsal CA3 hippocampal area. It led us to choose the $0.25-\mathrm{nmol}$ dose that causes significant performance impairments without marked side effects, and to establish the time course of DCG-IV effects in the CA3 area. The maximum effect is reached $15 \mathrm{~min}$ after injection and lasts for $3 \mathrm{~h}$. Thus, DCG-IV action on synaptic transmission could be behaviorally observed up to $3 \mathrm{~h}$ after infusion, so one should consider that when injected before conditioning, DCG-IV may act both on acquisition and consolidation processes of contextual memory, whereas when injected after the conditioning session, it can act only on the consolidation process.

Injection of DCG-IV in the CA3 area resulted in a large impairment of freezing response to the context. This finding corroborates those obtained in a previous study (Daumas et al. 2005) using lidocaine to block the entire CA3 region. CA3 can thus be ascribed a prominent role in contextual information processing. Indeed, the microinjection of DCG-IV into CA3 blocks both the direct (PP-CA3) and indirect (DG-MF-CA3) pathways from the entorhinal cortex. The only synapse liable to function in these conditions would be the synapse of the recurrent collaterals to the pyramidal cells (RC-CA3), although it is very unlikely that this pathway displays a strong synaptic activity, since it is supposed to be dependent upon the activity of the two other CA3 synapses (Zalutsky and Nicoll 1990). As a result, the CA3 network would be entirely inactivated by DCG-IV, as it is by lidocaine, except that lidocaine also blocks the electrical activity of crossing fibers.

Injection of DCG-IV in the DG either before or after the conditioning session also resulted in a substantial impairment of contextual memory. A study by Lee and Kesner (2004) is contradictory to our findings. Using a 10-trial learning procedure of contextual fear conditioning in the rat, they concluded that DG was not involved in contextual memory formation. Nevertheless, detailed examination of their results shows that after the first block of conditioning, i.e., after administering three CS-US pairings, rats with colchicine-induced DG lesions displayed a significantly lower level of freezing than controls, which is consistent with our results. Indeed, the inhibition of synaptic activity at the PP-DG synapse causes both the inability of information processing in the DG and the silencing of the MF-CA3 pathway, resulting in the dysfunction of the CA3 autoassociative network (although inputs from the direct PP-CA3 are still available) combined with an impoverishment of the information conveyed to the CA1 area by the Schaffer collaterals.

Blockade of direct PP-CA1 inputs by DCG-IV had no significant effect on CFC performance, whatever the time of injection. This contrasts with the effects of the complete CA1 blockade by lidocaine, which resulted in an impairment of context fear (Daumas et al. 2005). This finding highlights the importance of the information process within the trisynaptic circuit. Complete blockade of both the direct PP-CA3 and indirect MF-CA3 inputs resulted in a slightly more pronounced decrease of context fear than disruption of the PP-DG inputs, whatever the time of injection. Although not significant, this moderate difference suggests that DG inactivation would be the principal component of the memory deficit observed in CA3-treated mice. The inhibition of this indirect pathway to CA3 would disrupt the autoassociative network that is thought to support the construction of configural 
representations, whereas the role played by the direct PP-CA3 pathway in the processing of contextual memory would not be pivotal during the acquisition and consolidation phases of CFC. Previous work using DEDTC, a zinc chelator, aimed to block the MF-CA3 synapse selectively (Daumas et al. 2004) supports this view.

In conclusion, we made use of the specific expression of mGluR2/3 in the hippocampal trisynaptic network to dissect the relative importance of entorhinal outputs in contextual memory processing. Our results demonstrate that disruption of the PP-DG inputs results in a contextual memory deficit similar to the memory deficit observed after disruption of the indirect MF-CA3 inputs. This outcome emphasizes the prominent role played by the DG-MF-CA3 pathway in the development of efficient contextual memories. On the other hand, inactivation of the direct PP-CA1 pathways showed that it is not mandatory for the acquisition and/or consolidation of CFC. One might now want to go a step further and correlate these behavioral findings with in vivo recordings of long-term potentiation in the different subfields of the hippocampus after DCG-IV infusion.

\section{Acknowledgments}

This work was supported by the Paul Sabatier University and CNRS. We thank Dr. Emma Wood for careful reading of the manuscript.

\section{References}

Anwyl R. 1999. Metabotropic glutamate receptors: Electrophysiological properties and role in plasticity. Brain Res Brain Res Rev 29: 83-120.

Cartmell J, Schoepp DD. 2000. Regulation of neurotransmitter release by metabotropic glutamate receptors. J Neurochem 75: 889-907.

Conn PJ, Pin JP. 1997. Pharmacology and functions of metabotropic glutamate receptors. Annu Rev Pharmacol Toxicol 37: 205-237.

Daumas S, Halley H, Lassalle JM. 2004. Disruption of hippocampal CA3 network: Effects on episodic-like memory processing in $\mathrm{C} 57 \mathrm{Bl} / 6 \mathrm{~J}$ mice. Eur J Neurosci 20: 597-600.

Daumas S, Halley H, Frances B, Lassalle JM. 2005. Encoding, consolidation and retrieval of contextual memory: Differential involvement of CA3 and CA1 hippocampal subregions. Learn Mem 12: 375-382.
Daumas S, Betourne A, Halley H, Wolfer DP, Lipp HP, Lassalle JM, Frances B. 2007. Transient activation of the CA3 Kappa opioid system in the dorsal hippocampus modulates complex memory processing in mice. Neurobiol Learn Mem 88: 94-103.

Franklin KBJ, Paxinos G. 1997. The mouse brain in stereotaxic coordinates. Academic Press, San Diego, CA.

Kamiya H, Shinozaki H, Yamamoto C. 1996. Activation of metabotropic glutamate receptor type $2 / 3$ suppresses transmission at rat hippocampal mossy fibre synapse. J Physiol 493: 447-455.

Kesner RP, Lee I, Gilbert P. 2004. A behavioral assessment of hippocampal function based on a subregional analysis. Rev Neurosci 15: 333-351.

Klausnitzer J, Manahan-Vaughan D. 2008. Frequency facilitation at mossy fiber-CA3 synapses of freely behaving rats is regulated by adenosine A1 receptors. J Neurosci 28: $4836-4840$.

Lee I, Kesner RP. 2004. Differential contributions of dorsal hippocampal subregions to memory acquisition and retrieval in contextual fearconditioning. Hippocampus 14: 66-76.

Nakazawa K, Quirk MC, Chitwood RA, Watanabe M, Yeckel MF, Sun LD, Kato A, Carr CA, Johnston D, Wilson MA, et al. 2002. Requirement for hippocampal CA3 NMDA receptors in associative memory recall. Science 297: 211-218.

Nakazawa K, McHugh TJ, Wilson MA, Tonegawa S. 2004. NMDA receptors, place cells and hippocampal spatial memory. Nat Rev Neurosci 5: 361372 .

Ohishi H, Neki A, Mizuno N. 1998. Distribution of a metabotropic glutamate receptor, mGluR2, in the central nervous system of the rat and mouse: An immunohistochemical study with a monoclonal antibody. Neurosci Res 30: 65-82.

Rolls ET, Kesner RP. 2006. A computational theory of hippocampal function, and empirical tests of the theory. Prog Neurobiol 79: 1-48.

Rolls ET, Treves A. 1998. Neural networks and brain function, p. 498. Oxford University Press, New York.

Rudy JW, Huff NC, Matus-Amat P. 2004. Understanding contextual fear conditioning: Insights from a two-process model. Neurosci Biobehav Rev 28: $675-685$.

Scanziani M, Salin PA, Vogt KE, Malenka RC, Nicoll RA. 1997. Usedependent increases in glutamate concentration activate presynaptic metabotropic glutamate receptors. Nature 385: 630-634.

Tsukamoto M, Yasui T, Yamada MK, Nishiyama N, Matsuki N, Ikegaya Y. 2003. Mossy fibre synaptic NMDA receptors trigger non-Hebbian longterm potentiation at entorhino-CA3 synapses in the rat. J Physiol 546: 665-675.

Zalutsky RA, Nicoll RA. 1990. Comparison of two forms of long-term potentiation in single hippocampal neurons. Science 248: 1619-1624.

Received March 17, 2009; accepted in revised form May 20, 2009. 


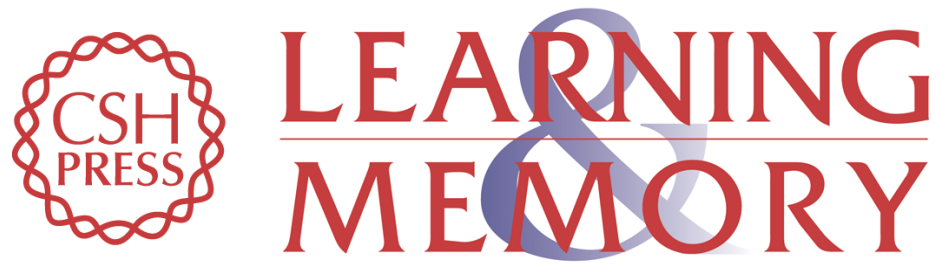

\section{Activation of metabotropic glutamate receptor type 2/3 supports the involvement of the hippocampal mossy fiber pathway on contextual fear memory consolidation}

Stéphanie Daumas, Johnatan Ceccom, Hélène Halley, et al.

Learn. Mem. 2009, 16:

Access the most recent version at doi:10.1101//m.1418309

References This article cites 18 articles, 4 of which can be accessed free at: http://learnmem.cshlp.org/content/16/8/504.full.html\#ref-list-1

License

Email Alerting

Receive free email alerts when new articles cite this article - sign up in the box at the Service top right corner of the article or click here. 